\title{
INTRA-GUILD COMPENSATION REGULATES SPECIES RICHNESS IN DESERT RODENTS
}

\author{
Jacob R. Goheen, ${ }^{1}$ Ethan P. White, ${ }^{2}$ S. K. Morgan Ernest,${ }^{2}$ and James H. Brown \\ Department of Biology, University of New Mexico, Albuquerque, New Mexico 87131 USA
}

\begin{abstract}
Evidence from numerous studies suggests that species richness is an emergent property of local communities. The maintenance of species richness, despite changes in species composition and environmental conditions, requires compensatory colonization and extinction events with species coming from a regional pool. Using long-term data from a rodent community in the Chihuahuan Desert, we use randomization methods to test the null hypothesis that changes in species richness occur randomly. We find that the dynamics of species richness differ significantly from a random process, and that these nonrandom dynamics occur largely within the most speciose guild. Finally, we propose a general framework for assessing the importance of species compensation in maintaining biodiversity within local communities. Our results highlight the importance of niche complementarity and compensation in maintaining relatively constant species richness over time.
\end{abstract}

Key words: Chihuahuan Desert, Portal, Arizona (USA); colonization-extinction dynamics; competition; desert rodents; local richness; randomization test; regional species pool; species compensation.

\section{INTRODUCTION}

Since MacArthur and Wilson (1967), much attention has been devoted to the idea that species richness arises as a consequence of a dynamic equilibrium between colonization and extinction. While originally formulated for oceanic islands, the theory has subsequently been applied to a wide variety of ecosystems, including mountains, nature reserves, and habitat patches (Brown 1971, Lomolino et al. 1989, Swihart et al. 2003). Much of this work has demonstrated that a dynamic equilibrium of species richness is unlikely for insular systems, where barriers to dispersal can restrict colonization from a regional pool (Brown and Lomolino 2000). In contrast, both colonization and extinction should operate most strongly in non-isolated systems, where local communities are exposed to relatively unrestricted immigration from a regional pool (Brown et al. 2001). Thus, by building upon the ideas first proposed by MacArthur and Wilson, ecologists have come to appreciate the general importance of large-scale processes in constraining the dynamics of local communities (e.g., Terborgh and Faaborg 1980, Cornell and Lawton 1992, Hubbell 2001, Collins et al. 2002, Sax et al. 2002, Stevens and Willig 2002).

In recent years, the significance of colonization and extinction to the maintenance of species richness in local communities has received renewed support from studies demonstrating temporal constancy in species richness. Apparent constancy in species richness has

Manuscript received 23 September 2004; revised 7 October 2004; accepted 7 October 2004. Corresponding Editor: A. M. Ellison.

${ }^{1}$ E-mail: jgoheen@unm.edu

2 Present address: Department of Biology, Utah State University, Logan, Utah 84322 USA. been noted in studies that encompass diverse taxa, geographic regions, and time scales (e.g., McNaughton 1977, Kelt 1996, Brown et al. 2001, Lekve et al. 2002). Furthermore, studies have shown that the species richness of a local community can remain relatively constant despite large changes in species composition (Frost et al. 1995, Ernest and Brown 2001a, Parody et al. 2001). This apparent constancy suggests the existence of dynamic processes that maintain species richness within narrow limits. Thus, determining whether richness does indeed exhibit constancy, and identifying the processes that regulate this constancy, are important steps toward understanding temporal dynamics of local communities.

Regulation of species richness involves interdependent local and regional processes (Brown et al. 2001). Colonization is an important link between these disparate scales (Loreau and Mouquet 1999, Holt and Keitt 2000), since the regional pool almost by definition contains species with a wider range of environmental tolerances than any local community. The regulation of species richness within communities has been proposed to occur if two conditions are met (Brown et al. 2001): (1) fluctuations in one or more environmental conditions, despite relatively constant resource availability; and (2) there is a feedback mechanism between the regional pool and local community, such that the probability of colonization increases when local richness falls below the long-term mean, and the probability of extinction increases when local richness exceeds the long-term mean. Lekve et al. (2003) refer to condition 1 as "extrinsic forcing" by the environment. Because species richness varies with resource availability across spatial scales (Wright et al. 1993), the stability of resource supply is essential for richness to

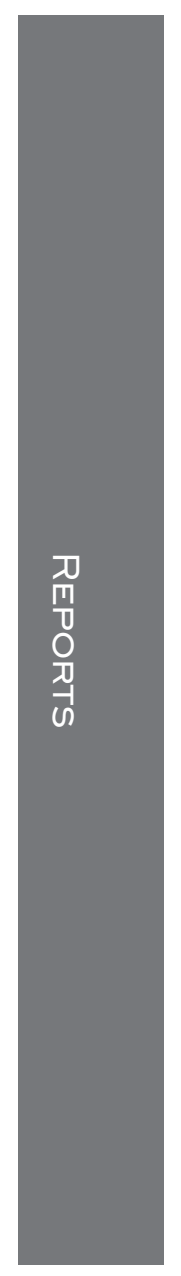




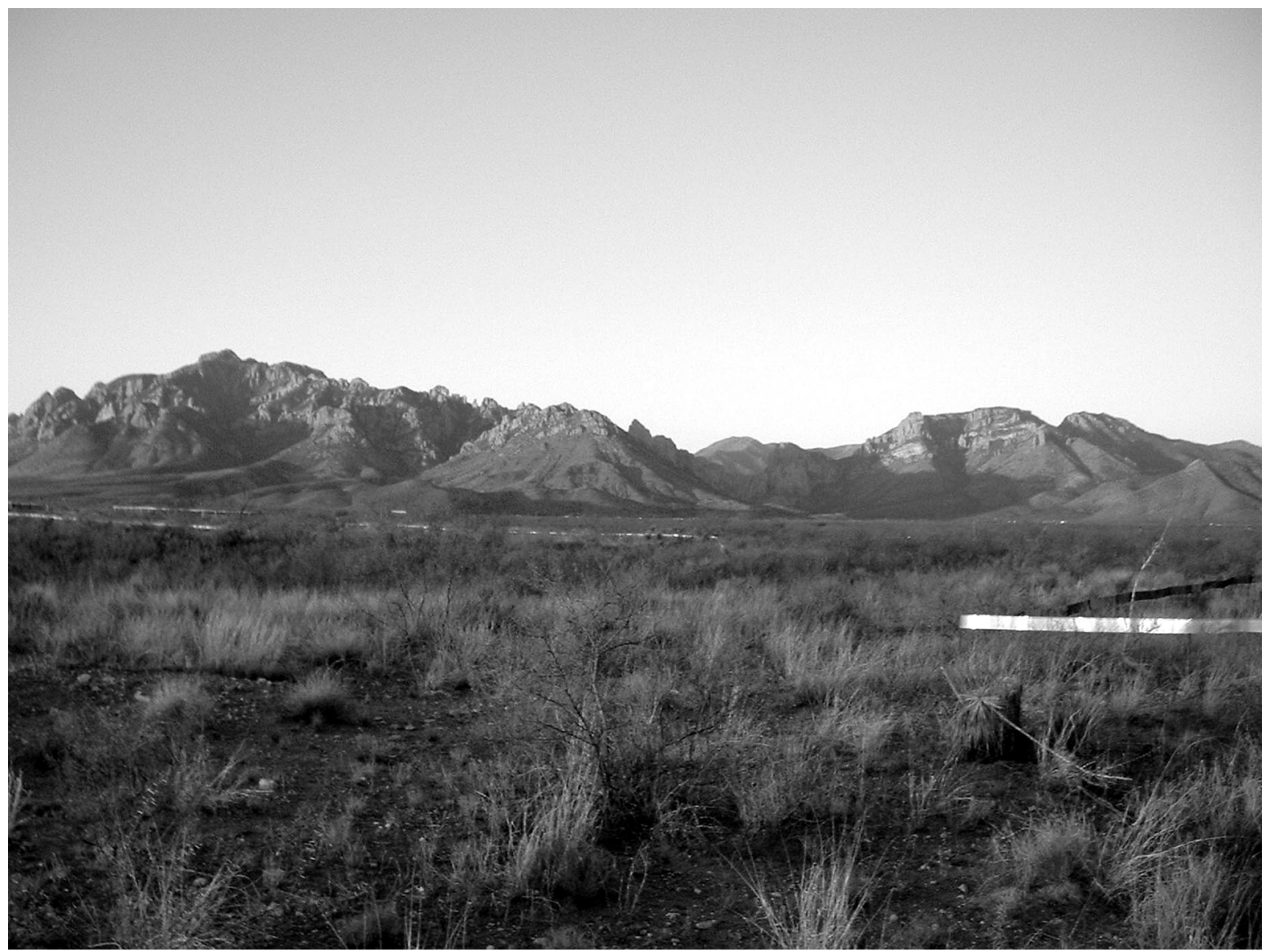

Plate. 1. The Portal Long-Term Research in Ecological Biodiversity site in southeastern Arizona, USA. Since 1977, experiments have been conducted on the interactions among rodents, annual plants, and ants. Study plots are fenced (see aluminum flashing in foreground) to manipulate access by particular groups of rodents. Recent investigations have focused on the analysis of community dynamics in response to long-term changes in vegetation and climate. Photo Credit: S. K. M. Ernest.

remain constant (Lekve et al. 2003). Condition 2 implies intrinsic regulation within the local community that serves to constrain species richness within narrow limits around some equilibrium. For the remainder of this paper, we focus on the role of intrinsic regulation in controlling species richness through time.

If changes in extrinsic, environmental conditions drive species turnover, and the ability of species to coexist is due in part to competition between species with similar but complementary requirements (MacArthur and Levins 1967, Root 1967), then we might expect compensatory colonization and extinction to occur most frequently within the same guild or functional group. This phenomenon has been demonstrated previously in local communities (Fox 1989, Fargione et al. 2003). Competitively superior species with lower resource requirements or higher efficiencies of resource use may exclude species of lesser competitive ability (Gause 1934, Tilman 1982). Moreover, if species in the regional pool can be sorted with regard to guild membership and competitive abilities under different en- vironmental conditions, fluctuations in these conditions will favor different combinations of species both within and between guilds (Chase and Leibold 2003). This implies that intra-guild compensation should be an important, intrinsic process regulating species richness within communities.

Our objectives in this paper are threefold. First, we evaluate if and to what extent apparent constancy in species richness in a desert rodent community is maintained via nonrandom colonization and extinction events. Second, we propose a novel method for quantifying the magnitude of species compensation in regulating species richness through time. Finally, we test the prediction that compensatory colonizations and extinctions occur largely within, rather than between, guilds.

\section{Materials And Methods}

We used data on the temporal dynamics of species richness from a 26-yr study (June 1977 to June 2003) of a rodent community in the Chihuahuan Desert near 
Portal, Arizona (see Plate 1). This community has undergone large changes in species composition, primarily in response to regional climate and vegetation change (Brown et al. 1997, 2001, Thibault et al. 2004). Rodents have been sampled monthly on 24 plots, each 0.25 ha in area. For the purposes of this investigation, we restricted analyses to the eight plots to which all species had equal access over the entire period. Because certain species sometimes hibernate during the winter months, we combined data into 6-mo periods (January-June and July-December), creating a total of 52 periods for analyses.

Each of the 21 species censused at the site was assigned to one of three guilds based on resource use: granivores (Baiomys taylori, Chaetodipus baileyi, C. hispidus, C. intermedius, C. penicillatus, Dipodomys merriami, D. ordii, D. spectabilis, Perognathus flavus, Peromyscus eremicus, Peromyscus leucopus, Peromyscus maniculatus, Reithrodontomys fulvescens, $R$. megalotis, R. montanus), herbivores (Neotoma albigula, Sigmodon fulviventer, S. hispidus, S. ochrognathus), and insectivores (Onychomys leucogaster, O. torridus). Over the course of the study, all species that could be expected to occur at the site (i.e., those species that occur in Chihuahuan Desert shrubland or arid grassland and whose geographic ranges overlap the site; Kays and Wilson 2002) have been captured at the site. Thus, the 21 species provide a good estimate of the size and composition of the regional pool.

We conducted randomizations to determine if the observed dynamics of species richness were different from those expected based on random colonization and extinction. We initialized each randomization with 10 species, the mean richness observed over the time series rounded to the nearest integer. Incidentally, this value is identical to the number of species sampled during the first 6-mo period. For each of the 51 subsequent time periods, we randomly drew an integer value for the net number of colonizations or extinctions (i.e., the net change in species richness) with replacement from the observed distribution. This effectively generated a random walk with a probability distribution of step lengths that includes steps of zero length (no change). We bounded this random walk between 0 and 21 species (i.e., between the logical minimum and the total number of species in the regional pool). This approach generates time series for species richness that, on average, will have the same mean (or median) species richness as the observed time series. Thus, our approach allows us to focus on the quantity of interest, which is the observed variability in species richness through time. For each randomization, we calculated two metrics of variation in species richness: the coefficient of variation (CV) and range of the values of species richness. We conducted 10000 randomizations and compared the $\mathrm{CV}$ and range of richness observed in the actual community to the resulting distributions. An observed CV and range significantly smaller than that obtained from our randomizations indicates reduced variation in species richness, and thus nonrandom species compensation. We determined the significance of this difference by calculating the proportion of randomizations with CVs and ranges less than the observed values. This approach focuses on net changes in species richness at a site through time, rather than on whether the colonizations, extinctions, or both tended to be compensatory (see Discussion).

In addition to determining whether or not regulation of species richness occurred, we evaluated the strength of species compensation by incorporating a compensation parameter (c) into our randomization procedure. This parameter increases the probability of a net colonization event or a net extinction event if richness is below or above the long-term mean, respectively. If species richness at a time step $t$ exceeded the mean species richness, then with probability $c$ the change in richness at the next step $t+1$ was drawn only from the observed distribution of net decreases, and with probability $1-c$ the change was drawn from the entire observed distribution. Similarly, if species richness at $t$ fell below the mean species richness, then the change in richness at $t+1$ was drawn only from the observed distribution of net increases with probability $c$, and from the entire observed distribution with probability $1-c$. If species richness at $t$ was equal to the longterm mean, changes were drawn without bias from the observed distribution. Thus, when the number of species present at $t$ deviates from the long-term mean, $c$ quantifies the tendency at $t+1$ for species richness to move toward this mean. For example, if $c=0.90$ and richness exceeds the long-term mean at $t$, there is a $90 \%$ chance that the change between $t$ and $t+1$ will be drawn only from the observed distribution of net decreases. Thus, the total probability that richness will decrease at $t+1=0.90+0.10$ (probability of a net decrease in the observed distribution). We let $c$ vary in increments of 0.05 from 0 and 1 , and inferred the strength of compensation by determining the value of $c$ at which $50 \%$ of the quasi-random walks had CVs greater than observed and $50 \%$ had CVs less than observed. In other words, we determined the value of $c$ for which the median CV of the randomizations matched the observed $\mathrm{CV}$, and considered this to be the best estimate of $c$ for the community.

Having demonstrated that compensation occurred, we conducted three additional sets of randomizations to determine whether compensation was due to processes operating within guilds. These randomizations were essentially identical to our previous ones, but with two exceptions. First, net values of the difference between colonization and extinction events were drawn only from the distribution of values for the particular guild of interest. Second, the upper bound for each set of randomizations corresponded with the number of species from the regional pool belonging to the guild of interest (15 for granivores, four for herbivores, and

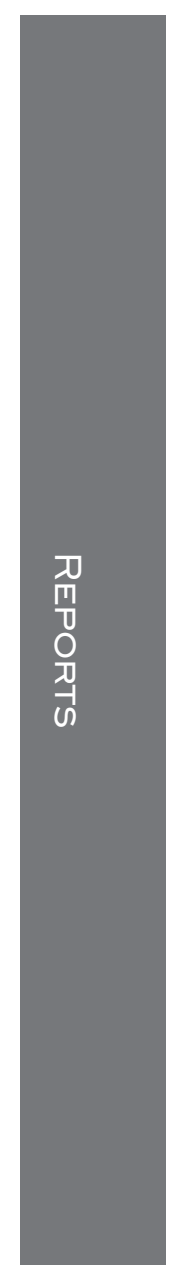



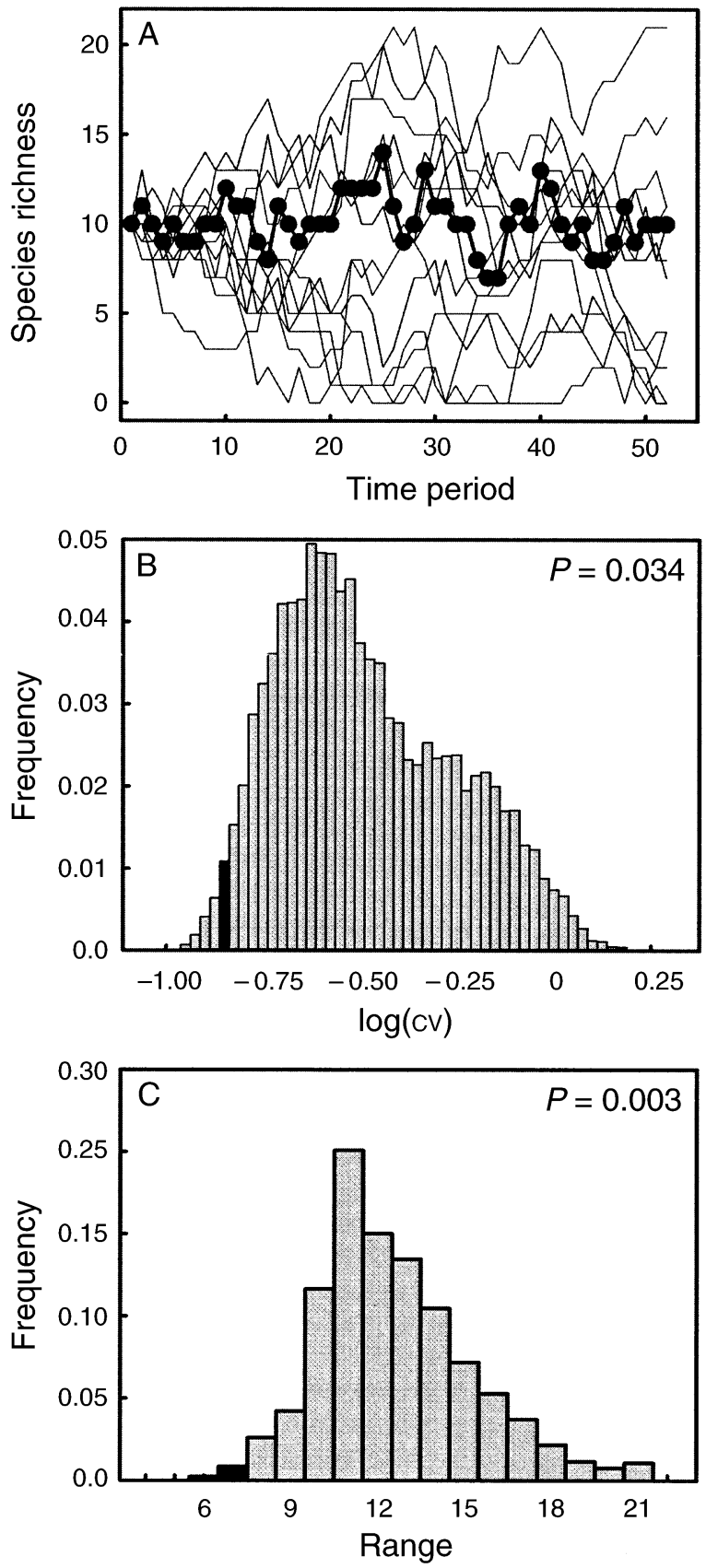

FIG. 1. Results from "quasi-random walk" randomizations. (A) The observed data for species richness through time at Portal, Arizona, USA (thick line with filled circles) are compared to 15 quasi-random walks (thin lines). Only 15 of the 10000 quasi-random walks are plotted for clarity. Histograms of (B) the coefficient of variation (CV) and (C) the range in species richness were generated via quasi-random walks. Black bars represent the observed $\mathrm{CV}$ and range at Portal, both of which are significantly lower than expected $(P=0.034,0.003$, respectively $)$. two for insectivores). We then calculated the CVs for each randomization for each of the three guilds, and compared the observed CVs to the resulting distributions (we did not use range in species richness because it is an insensitive measure of variation with small subsets of species). Observed CVs smaller than expected from this guild test would support the hypothesis that compensation occurs largely within guilds, so that competition for resources plays a significant role in regulating species richness through time.

\section{RESULTS}

Observed richness varied from seven to 14 species. There was substantially more variation in the "quasirandom walks" (Fig. 1A). The observed CV and range of species richness values were significantly lower than for the randomizations (Fig. 1B, C), indicating that species compensation served to regulate richness through time (randomized $\log [\mathrm{CV}]=-0.46 \pm 0.24$ $[$ mean $\pm 1 \mathrm{SD}]$, observed $\log [\mathrm{CV}]=-0.84, P=0.034$; randomized range $=12.02 \pm 2.54$, observed range $=$ 7, $P=0.003$ ).

The magnitude of the compensatory process was sizeable, giving a compensation index of approximately 0.70 . The proportion of randomizations with CVs less than or greater than the observed CV (i.e., the minimum of these two values) increased gradually with $c$, peaked at $c \approx 0.70$, and then declined as $c$ approached 1.0 (Fig. 2).

Species richness within the granivore guild was significantly more constrained than expected from the randomizations ( $P=0.026$; Fig. 3A). In the herbivore and insectivore guilds, observed CVs were near the mode of the randomized distributions $(P>0.20$; Fig. 3B, C).

\section{DISCUSSION}

The dynamics of extinction and colonization from a regional pool can be strong forces regulating local spe-

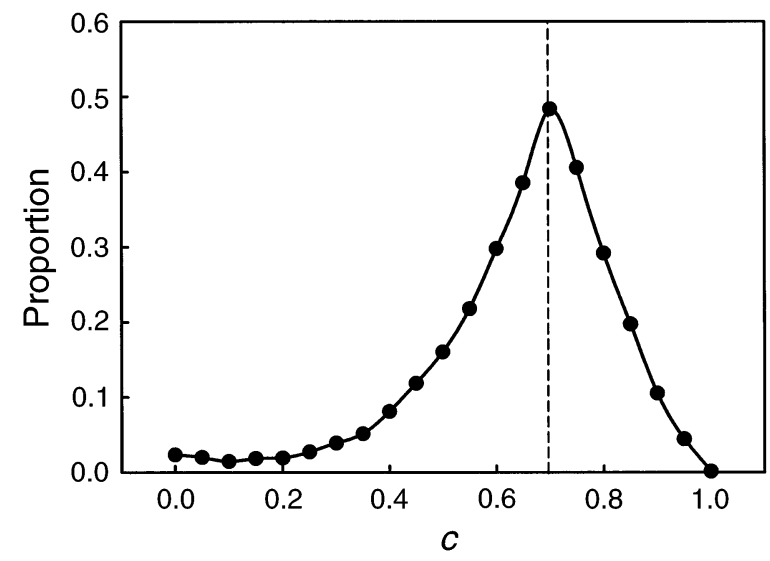

FIG. 2. Change in the proportion of coefficients of variation (Cvs) generated using quasi-random walks that were either less than or greater than the observed CV (the minimum of these two values) as a function of $c$. The dashed line represents the estimate of $c$ for Portal, Arizona. 

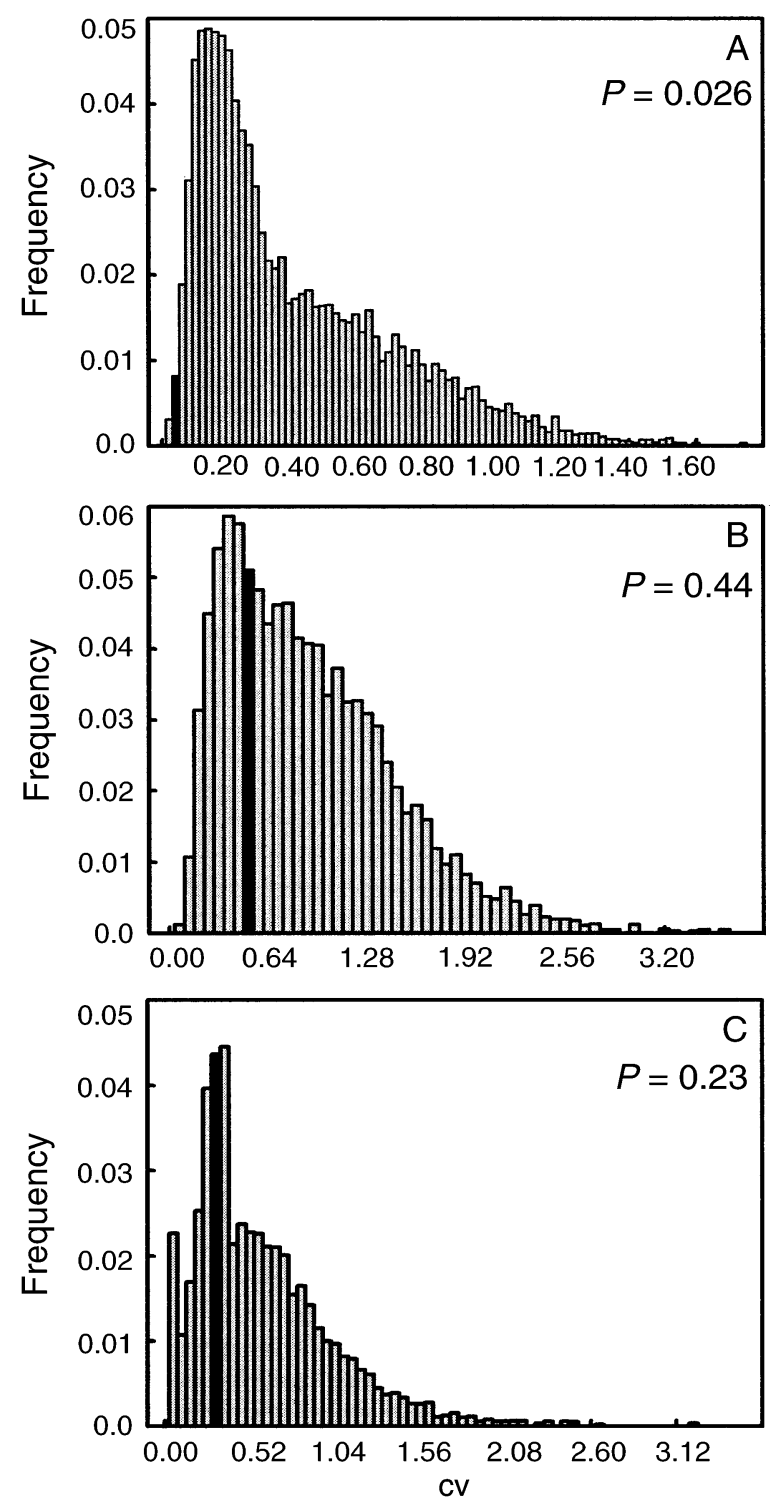

FIG. 3. Results from "quasi-random walk" randomizations for (A) granivores, (B) herbivores, and (C) insectivores. Black bars represent the observed CVs; the CV is significantly lower than expected in the granivore guild.

cies richness (MacArthur and Wilson 1967, Simberloff and Wilson 1969, Ricklefs and Schluter 1993, Hubbell 2001). In this community, colonization and extinction events were compensatory, not random. Species richness for the entire community is maintained by compensatory colonization and extinction, which occurs primarily within the most speciose guild. Compensation between granivore species occurred significantly more frequently than expected by chance. These results indicate that constancy in local species richness can emerge as a consequence of intrinsic regulation of richness, and that a "carrying capacity" for species within a community (Brown et al. 2001, Lekve et al. 2003) can emerge from the collective carrying capacities of one or more constituent guilds.

In our study system, species richness was constrained in the granivore guild. Because rodents are responsible for the majority of seed consumption in desert communities (Brown et al. 1979), compensation of granivores in this taxon should be most notable in the granivore guild. Further, the majority of species in the regional pool are granivores. At Portal, this rich regional pool almost certainly facilitated compensation. For example, extinctions of species with preferences for grassland habitats (e.g., D. spectabilis, $P$. flavus, Reithrodontomys spp.) have coincided with colonizations of species with affinities for shrubby habitats (e.g., C. baileyi, C. penicillatus; Ernest and Brown 2001b, Thibault et al. 2004). Given that species richness was constrained for the entire community, we might expect apparent compensatory dynamics to arise in any moderately large grouping of species, regardless of guild membership. Such statistical issues are difficult to distinguish from ecological patterns because the species pool is dominated by granivores. However, experimental studies in our system have documented direct competition among granivores, while interactions between granivores and other guilds were negligible (Heske et al. 1994, Valone and Brown 1995). If anything, this suggests that the overall community pattern is being driven by granivores, not the other way around.

In contrast, dynamics of species richness within the insectivore and herbivore guilds did not differ from a random walk process. However, the number of rodent species occurring in the regional pool for both guilds is low, and their median annual species richness is only a single species. Thus, modest compensatory dynamics may be obscured by the statistics of small numbers, and we cannot be confident that the difference between granivores and other guilds is real. Given this limitation (and the fact that failing to reject a null hypothesis does not allow us to accept it) these results should be interpreted with some caution. That stated, it is worth noting that rodents do not comprise either the dominant herbivores or insectivores at Portal and, as such, might be less likely to display compensatory dynamics. Lizards (e.g., Sceloporus spp., Phrynosoma spp.) are the most common insectivores in our study system, while larger mammals (e.g., desert cottontails [Sylvilagus audoboni], mule deer [Odocoileus hemionus], javelina [Tayassu tajacu]) probably are more important than rodents in plant consumption (J. H. Brown, personal observation). Thus, colonization-extinction dynamics of rodents in these guilds is likely to be governed in part by competition with other taxa.

The compensatory dynamics observed in the granivore guild could occur in two distinct ways, although these need not be exclusive. First, if local extinction causes the number of species within a guild to fall below the guild carrying capacity, resources are available to support new colonizing species and intra-guild 
compensation should occur. This assumes a change in one or more environmental variables such that, following the initial extinction event, utilization of remaining resources requires colonization by a new species; this is a distinct process from compensation by species that were present already (i.e., density compensation, Root 1973). Alternatively, a colonization event could occur, causing the number of species within a guild to exceed the guild carrying capacity. In this scenario, the suite of species present in the guild may no longer be sufficiently distinct in resource use to coexist, leading to a local extinction event (MacArthur and Levins 1967). Our analyses show that these types of compensatory dynamics seem to be operating in our study system and lead to a dynamic equilibrium of species richness (sensu Huston 1979). However, our analyses do not enable us to distinguish between these two different processes.

These types of compensatory dynamics require both a diverse regional pool and a high rate of exchange between the local community and the pool. If colonization rates are low (due to inherently low dispersal rates, extrinsic environmental barriers to dispersal, etc.), then long lags between extinction and colonization should occur (Brown 1971, Loreau and Mouquet 1999, Heaney 2000, Levine and Rees 2002, Sax et al. 2002). However, even if colonization rates are high, compensation for local extinctions is expected only when the regional pool contains species that overlap in resource use with the extinct species, but differ with respect to the utilization of some other niche axis- the one that changed to cause the extinction (Ernest and Brown 2001a, Chase and Leibold 2003). The tendency for species to have similar requirements on one niche axis, but to differ on another is often referred to as niche complementarity (sensu Schoener 1974). Alternatively, if colonization augments the number of species within a guild such that those species are not sufficiently distinct in resource use, local extinction should occur, and the best competitors will inhibit the further persistence of inferior competitors (MacArthur and Levins 1967).

The interaction between regional richness, niche complementarity, and dispersal rate should determine the strength of compensation. Here we have used $c$ to index the strength of compensatory colonization and extinction. Since $c$ is bounded (0 to 1$)$, it provides a useful metric for quantifying the strength of species compensation within a community. A $c$ value of 1.0 indicates that species richness will always move toward its average long-term carrying capacity after the addition or deletion of species, whereas a $c$ value of zero indicates completely random colonization and extinction events. At Portal, $c$ was approximately equal to 0.7 , indicating strongly compensatory dynamics. As discussed above, low colonization rates or low regional diversity would be expected to decrease the strength of compensation, and thus to decrease the value of $c$. Future work using $c$ to evaluate the effects of dispersal ability, niche complementarity, and regional richness on local richness regulation could prove very insightful.

Understanding the processes that generate and maintain species richness at the level of communities is a fundamental area of ecological research. Our results support the notion of community saturation; that is, the importance of local processes, such as competition, in imposing an upper limit on the number of species that can co-occur locally (Huston 1999, Mouquet et al. 2003). Our results run counter to ideas that species richness is determined primarily by historic and regional processes, and that local ecological interactions play a minor role at best (e.g., Ricklefs 2004). Future research examining the interaction between saturation and colonization rates may provide insight into this long-standing debate. As such, more work is needed to determine when local regulation of richness is likely to be strong, and what mechanisms are responsible. Further exploration and development of these ideas should enhance our understanding of the responses of communities to natural and anthropogenic perturbations.

\section{ACKNOWLEDGMENTS}

Aaron Ellison and two anonymous reviewers provided critical comments that improved the rigor and quality of this manuscript. We thank A. Ernest and the many volunteers and assistants who have worked at Portal. We thank A. P. Allen, K. M. Thibault, A. H. Hurlbert, C. M. McClain, and R. D. Stevens for comments and discussion. We would especially like to thank Jason Bragg for recommending the use of a parameter to measure compensation. The Portal Project is an NSF LTREB site and has been supported most recently by NSF DEB-0129298. This project was supported by an NSF Biocomplexity grant (DEB-0083422). J. R. Goheen was also supported by an EPA STAR graduate fellowship. E. P. White was also supported by an NSF Graduate Research Fellowship.

\section{Literature Cited}

Brown, J. H. 1971. Mammals on mountaintops: non-equilibrium insular biogeography. American Naturalist 105:467478.

Brown, J. H., S. K. M. Ernest, J. M. Parody, and J. P. Haskell. 2001. Regulation of diversity: maintenance of species richness in changing environments. Oecologia 126:321-332.

Brown, J. H., and M. V. Lomolino. 2000. Concluding remarks: historical perspective and the future of island biogeography theory. Global Ecology and Biogeography 9: 87-92.

Brown, J. H., O. J. Reichman, and D. W. Davidson. 1979. Granivory in desert ecosystems. Annual Review of Ecology and Systematics 10:207-227.

Brown, J. H., T. J. Valone, and C. G. Curtin. 1997. Reorganization of an arid ecosystem in response to recent climate change. Proceedings of the National Academy of Science (USA) 94:9729-9733.

Chase, J. M., and M. A. Leibold. 2003. Ecological niches. Chicago University Press, Chicago, Illinois, USA.

Collins, S. L., S. M. Glenn, and J. M. Glenn. 2002. Effect of local and regional processes on plant species richness in tallgrass prairie. Oikos 99:571-579.

Cornell, H. V., and J. H. Lawton. 1992. Species interactions, local and regional processes, and limits to the richness of ecological communities: a theoretical perspective. Journal of Animal Ecology 61:1-12. 
Ernest, S. K. M., and J. H. Brown. 2001a. Homeostasis and compensation: the role of species and resources in ecosystem stability. Ecology 82:2118-2132.

Ernest, S. K. M., and J. H. Brown. 2001b. Delayed compensation for missing keystone species by colonization. Science 292:101-104.

Fargione, J., C. S. Brown, and D. Tilman. 2003. Community assembly and invasion: an experimental test of neutral versus niche processes. Proceedings of the National Academy of Science (USA) 100:8916-8920.

Fox, B. J. 1989. Small-mammal community pattern in Australian heathland: a taxonomically-based rule for species assembly. Pages 91-103 in D. W. Morris, Z. Abramsky, B. J. Fox, and M. R. Willig, editors. Patterns in the structure of mammalian communities. Texas Tech University Press, Lubbock, Texas, USA.

Frost, T. M., S. R. Carpenter, A. R. Ives, and T. K. Kratz. 1995. Species compensation and complementarity in ecosystem function. Pages 224-239 in C. G. Jones and J. H. Lawton, editors. Linking species and ecosystems. Chapman and Hall, New York, New York, USA.

Gause, G. F. 1934. The struggle for existence. Hafner, New York, New York, USA.

Heaney, L. R. 2000. Dynamic disequilibrium: a long-term, large-scale perspective on the equilibrium model of island biogeography. Global Ecology and Biogeography 9:59-74.

Heske, E. J., J. H. Brown, and S. Mistry. 1994. Long-term experimental study of a Chihuahuan Desert rodent community: 13 years of competition. Ecology 75:438-445.

Holt, R. D., and T. H. Keitt. 2000. Alternative causes for range limits: a metapopulation perspective. Ecology Letters 3:41-47.

Hubbell, S. P. 2001. The unified neutral theory of biodiversity and biogeography. Monographs in Population Biology Number 32. Princeton University Press, Princeton, New Jersey, USA.

Huston, M. A. 1979. A general hypothesis of species diversity. American Naturalist 113:81-101.

Huston, M. A. 1999. Local processes and regional patterns: appropriate scales for understanding variation in the diversity of plants and animals. Oikos 86:393-401.

Kays, R. W., and D. E. Wilson. 2002. Mammals of North American. Princeton University Press, Princeton, New Jersey, USA.

Kelt, D. A. 1996. Ecology of small mammals across a strong environmental gradient in southern South America. Journal of Mammalogy 77:205-219.

Lekve, K., T. Boulinier, N. C. Stenseth, J. Gjøsæter, J. M. Fromentin, J. E. Hines, and J. D. Nichols. 2002. Spatiotemporal dynamics of species richness in coastal fish communities. Proceedings of the Royal Society London B 269 : 1781-1789.

Lekve, K., N. C. Stenseth, R. Johansen, O. C. Lingjærde, and J. Gjøsæter. 2003. Richness dependence and climatic forcing as regulating processes of coastal fish-species richness. Ecology Letters 6:428-439.

Levine, J. M., and M. Rees. 2002. Coexistence and relative abundance in annual plant assemblages: the roles of competition and colonization. American Naturalist 160:452467.

Lomolino, M. V., J. H. Brown, and R. Davis. 1989. Island biogeography of montane forest mammals in the American Southwest. Ecology 70:180-194.
Loreau, M., and N. Mouquet. 1999. Immigration and the maintenance of local species diversity. American Naturalist 154:427-440.

MacArthur, R. H., and R. Levins. 1967. The limiting similarity, convergence, and divergence of coexisting species. American Naturalist 101:377-385.

MacArthur, R. H., and E. O. Wilson. 1967. The theory of island biogeography. Princeton University Press, Princeton, New Jersey, USA.

McNaughton, S. J. 1977. Diversity and stability of ecological communities: a comment on the role of empiricism in ecology. American Naturalist 111:515-525.

Mouquet, N., P. Munguia, J. M. Kneitel, and T. E. Miller. 2003. Community assembly time and the relationship between local and regional species richness. Oikos 103:618626.

Parody, J. M., F. J. Cuthbert, and E. H. Decker. 2001. The effect of 50 years of landscape change on species richness and community composition. Global Ecology and Biogeography 10:305-313.

Ricklefs, R. E. 2004. A comprehensive framework for global patterns in biodiversity. Ecology Letters 7:1-15.

Ricklefs, R. E., and D. Schluter, editors. 1993. Species diversity in ecological communities: historical and geographical perspectives. University of Chicago Press, Chicago, Illinois, USA.

Root, R. B. 1967. The niche exploitation pattern of the Bluegray Gnatcatcher. Ecological Monographs 37:317-349.

Root, R. B. 1973. Organization of a plant-arthropod association in simple and diverse habitats: fauna of collards (Brassica oeracea). Ecological Monographs 43:95-124.

Sax, D. F., S. D. Gaines, and J. H. Brown. 2002. Species invasions exceed extinctions on islands worldwide: a comparative study of plants and birds. American Naturalist 160: 766-783.

Schoener, T. W. 1974. Resource partitioning in ecological communities. Science 185:27-39.

Simberloff, D. S., and E. O. Wilson. 1969. Experimental zoogeography of islands: the colonization of empty islands. Ecology 50:278-296.

Stevens, R. D., and M. R. Willig. 2002. Geographical ecology at the community level: perspectives on the diversity of new world bats. Ecology 83:545-560.

Swihart, R. K., T. C. Atwood, J. R. Goheen, D. M. Scheiman, K. E. Munroe, and T. M. Gehring. 2003. Patch occupancy of North American mammals: is patchiness in the eye of the beholder? Journal of Biogeography 30:12591279.

Terborgh, J. W., and J. Faaborg. 1980. Saturation of bird communities in the West Indies. American Naturalist 116: 178-195.

Thibault, K. M., E. P. White, and S. K. M. Ernest. 2004. Temporal dynamics in the structure and composition of a desert rodent community. Ecology 85:2649-2655.

Tilman, D. 1982. Resource competition and community structure. Princeton University Press, Princeton, New Jersey, USA.

Valone, T. J., and J. H. Brown. 1995. Effects of competition, colonization, and extinction on rodent species diversity. Science 276:880-883.

Wright, D. H., D. J. Currie, and B. A. Maurer. 1993. Energy supply and patterns of richness on local and regional scales. Pages 66-74 in R. E. Ricklefs and D. Schluter, editors. Species diversity in ecological communities. University of Chicago Press, Chicago, Illinois, USA. 